\title{
DETERMINAÇÃO DE PROPRIEDADES TÉRMICAS DE GRÃOS DE MILHO
}

\author{
Determination of corn thermal properties
}

\author{
Ednilton Tavares de Andrade ${ }^{1}$, Sandra Maria Couto², Daniel Marçal de Queiroz ${ }^{2}$, Abraão Brito Peixoto ${ }^{3}$
}

\begin{abstract}
RESUMO
Realizou-se este trabalho com o objetivo de determinar a massa específica, condutividade térmica, difusividade térmica e calor específico de grãos de milho, em função do teor de água do produto. Na determinação da condutividade e da difusividade térmicas, foi usado o método do cilindro infinito dotado de uma fonte de calor linear central. Para tal, foi construído um equipamento que consistiu de um tubo de alumínio ( $0,1 \mathrm{~m}$ de diâmetro e $0,5 \mathrm{~m}$ de altura) isolado nas extremidades superior e inferior. Para funcionar como fonte linear de calor, instalou-se no centro do cilindro (na direção longitudinal) um fio resistor de níquelcromo envernizado (resistência, aproximada, $4,16 \Omega \cdot \mathrm{m}^{-1}$ ), com diâmetro de $0,0006438 \mathrm{~m}$. Durante cada determinação, o fio resistor foi submetido a uma diferença de potencial de $2,08 \mathrm{~V}$ (fonte alimentadora de tensão e voltagem), que proporcionou uma corrente elétrica de $1 \mathrm{~A}$. O teor de água das amostras testadas variou de 8,6 a 17,1\% b.u. O comportamento dos valores de condutividade térmica, difusividade térmica e calor específico em função do teor de água no produto pode ser representados por relações lineares. A condutividade térmica e o calor específico dos grãos aumentaram com o teor de água do produto, enquanto a difusividade térmica diminuiu. Erros envolvidos nas determinações das propriedades térmicas são também discutidos neste trabalho.
\end{abstract}

Termos para indexação: Condutividade térmica, calor específico, grãos de milho.

\begin{abstract}
Values for bulk density, thermal conductivity, thermal diffusivity and specific heat of corn grains were obtained in this work as a function of product moisture content. The infinite cylinder method with a central heat source was used in the thermal conductivity and diffusivity determinations. The equipment used consisted of an aluminum tube $(0.1 \mathrm{~m}$ of diameter and $0.5 \mathrm{~m}$ of height) isolated in the superior and inferior extremities. A resistor (nickel-chrome; strength of $4.16 \mathrm{~W} . \mathrm{m}^{-1}$; diameter of $0.0006438 \mathrm{~m}$ ) was used as a heat source that was located at the center of the cylinder (longitudinal direction). During each determination, the resistor was submitted to a difference of potential of $2.08 \mathrm{~V}$ that provided an electric current of $1 \mathrm{~A}$. The moisture content of the tested samples varied from 8.6 to $17.1 \%$ w.b. The behavior of the values of thermal conductivity, diffusivity and specific heat as a function of the product moisture content can be represented by linear relationships. The thermal conductivity and specific heat of the grains increase with the product moisture content, while the thermal diffusivity decreases. Errors involved in the thermal properties determinations are also discussed in this work.
\end{abstract}

Index terms: Thermal conductivity, specific heat, corn grains.

(Recebido para publicação em 20 de janeiro de 2003 e aprovado em 15 de abril de 2003)

\section{INTRODUÇÃO}

O mecanismo de transferência de calor por condução, normalmente, é interpretado como uma propagação da energia cinética pelas oscilações moleculares. Quando a energia cinética aumenta, com a elevação da temperatura, essa é transferida às moléculas circunvizinhas.

Nos processos de secagem e armazenamento de grãos agrícolas, a transferência de calor geralmente ocorre em massas de produto, compostas de grãos e ar. O conhecimento de valores das propriedades térmicas de tais leitos porosos, denominadas propriedades aparentes, é essencial para a predição da distribuição de temperatura no interior da massa de grãos (ROSSI et al., 1982). As propriedades térmicas mais relevantes, nesse caso, são condutividade térmica, difusividade térmica e calor específico do produto (ROSSI e ROA, 1980).

Em um material homogêneo, o calor se difunde com a mesma velocidade em todas as direções, e as propriedades térmicas não dependem do volume ou da forma do material examinado. Entretanto, quando se trata de um material heterogêneo como uma massa de grãos (material granular e higroscópico), a forma das

\footnotetext{
1. Professor Adjunto, D.S., Departamento de Engenharia Civil, Universidade Federal Fluminense, Rua Passo da Pátria 156, São Domingos - Niterói, RJ - 24210-240 - (0xx) 21 2629-5389, ednilton@civil.uff.br.

2. Professor Adjunto, Departamento de Engenharia Agrícola, Universidade Federal de Viçosa - 36571-000 - Viçosa, MG.

3. Estudante de Graduação em Engenharia de Alimentos, UFV.
} 
partículas e a compactação do produto influenciam na quantidade de calor transferido por unidade de área. As propriedades térmicas de um material são influenciadas, também, pelo teor de água do produto, temperatura, composição, densidade e porosidade (STOLF, 1972).

A condutividade térmica, no caso de uma transferência de calor unidimensional, pode ser definida por meio da lei de Fourier, expressa como:

$$
q=-k A \frac{d T}{d x}
$$

em que q é a quantidade de calor dissipado no sistema (W), k é condutividade térmica $\left(\mathrm{W} \cdot \mathrm{m}^{-1} \cdot{ }^{\circ} \mathrm{C}^{-1}\right)$, T é a temperatura $\left({ }^{\circ} \mathrm{C}\right)$, A é a área $\left(\mathrm{m}^{2}\right)$, e x é a distância da fonte de calor ao ponto de interesse $(\mathrm{m})$.

Basicamente, os métodos para determinação da condutividade térmica de um material baseiam-se na investigação do processo de transferência de calor, em regime permanente ou transiente, por condução em uma amostra do produto modelada com uma forma geométrica simples (placas paralelas, cilindros e esferas concêntricas). A geometria e as condições impostas ao sistema para a transferência de calor são similares àquelas que teoricamente descrevem um problema, regido por uma equação diferencial, que tenha uma solução analítica. Nos experimentos, quando o material é granular, esse é inserido em recipiente de forma geométrica simples e submetido a um gradiente de temperatura. A temperatura em diferentes pontos do sistema, durante o processo de transferência de calor, é registrada e introduzida na expressão que representa a solução da equação de difusão, propiciando, assim, a obtenção da condutividade térmica aparente do material.

A maioria dos valores de condutividade térmica de grãos, disponíveis na literatura, foi obtida submetendo-se o meio a um processo de condução de calor em regime permanente. De modo geral, esse não é um método considerado apropriado para produtos biológicos, em razão dos longos intervalos de tempo necessários para que um regime permanente seja atingido. Nesse período, podem ocorrer modificações significativas no teor de água do produto. A transferência de massa é mais pronunciante quando existe uma diferença de temperatura em um meio úmido e permeável.

A massa específica aparente ou densidade de produtos granulares (grau de compactação dos grãos) influencia, também, a condutividade térmica da amostra, que aumenta com diminuições na porosidade da amostra granular. Considerando um teor de água constante, a condutividade térmica pode ser uma função linear da massa específica (JAYAS et al., 1995). De ma- neira geral, a condutividade térmica de um material se eleva com a temperatura ou teor de água.

Existem muitas referências na literatura nas quais se discutem vários tipos de montagens empregadas na medição da condutividade térmica de alimentos e grãos. Um dos métodos mais usados, atualmente, para determinação da condutividade térmica de produtos agrícolas é baseado na transmissão de calor num cilindro infinito com uma fonte de calor linear central. Essa transferência pode ser analisada em regimes permanentes ou transientes. Esse método consiste na utilização de um cilindro (receptor da amostra de grãos), construído com material resistente e de alta condutividade térmica, de diâmetro e comprimento pré-determinados. Longitudinalmente, no centro do cilindro, coloca-se um fio de resistência elétrica conhecida (fonte linear de calor), que será percorrido por uma corrente (baixa amperagem) quando submetido a uma diferença de voltagem. A variação de temperatura do meio é registrada por meio de termopares situados preferencialmente à meia altura do cilindro.

O cilindro infinito é uma idealização que possibilita adotar a hipótese da condução unidimensional na direção radial. A aproximação é razoável se o cilindro tiver relação entre a altura e o raio maior ou igual a 10 (INCROPERA e WITT, 1996).

O equilíbrio térmico do sistema (cilindro infinito e grãos) é essencial para que os testes sejam iniciados. Além disso, fatores de correção para a inércia térmica do sistema devem ser considerados.

Uma importante fonte de erro a ser observada em tal metodologia é a migração de umidade de locais próximos à fonte de calor para as bordas do sistema, em conseqüência das regiões de temperaturas diferentes. A maneira de se minimizar esse erro é utilizar correntes baixas na resistência elétrica, propiciando, assim, menores gradientes de temperatura no produto. Outra fonte de erro nessa metodologia é a incerteza envolvida na posição de fixação dos termopares.

O mesmo equipamento (cilindro infinito), usado para a determinação da condutividade em regime permanente, tem sido utilizado por vários pesquisadores para determinação da condutividade térmica em grãos agrícolas, utilizando o método do regime transiente (HOOPER e LEPPER, 1950; DICKERSON, 1965; MUIR e CHANDRA, 1970; CHANDRA e MUIR, 1971; REIDY e RIPPEN, 1971; JASANSKY e BILANSKI, 1973; SHARMA e THOMPSOM, 1973; SUTER et al., 1975; ALMEIDA, 1979; PASSOS, 1982; SINGH, 1982; DROUZAS e SARAVACOS, 1988; 
SOARES, 1988; MAROULIS et al., 1991; VOUDOURIS e HAYAKAWA, 1994; FANG et al., 1997).

Para determinado fluxo de calor, seguindo o procedimento de Hooper e Lepper (1950), pode-se avaliar a condutividade do material conhecendo-se os valores de temperatura em um ponto, especificado a partir da fonte linear de calor, nos tempos $t_{1}$ e $t_{2}$, por meio da equação:

$$
\Delta T=\frac{-Q}{4 \pi k} \ln \left(\frac{t_{2}}{t_{1}}\right)
$$

em que $\Delta T$ é a variação de temperatura no ponto especificado $\left({ }^{\circ} \mathrm{C}\right), \mathrm{Q}$ é a potência dissipada na fonte linear de calor $\left(\mathrm{W} \cdot \mathrm{m}^{-1}\right), \mathrm{k}$ é a condutividade térmica $\left(\mathrm{W} \cdot \mathrm{m}^{-1} \cdot{ }^{\circ} \mathrm{C}^{-1}\right), \mathrm{t}_{1}$ e $\mathrm{t}_{2}$ são os tempos inicial e final (s).

Materiais biológicos, tipicamente, exibem algumas características que dificultam o uso da técnica da fonte linear de calor. Entre essas, citam-se: (a) distribuição heterogênea e anisotrópica dos grãos no cilindro (massa de grãos é um meio poroso e é constituída, muitas vezes, de grãos de diferentes tamanhos); (b) significativa resistência de contato entre a interface partícula-ar; (c) migração de calor latente devida à evaporação da água nos poros.

Correções, que consideram a oscilação inicial da fonte de calor e o aquecimento inicial do sistema, têm sido feitas por muitos pesquisadores, utilizando-se um fator de correção, $\tau_{0}$, que deve ser subtraído de cada tempo experimental constante na equação 3 .

$$
\Delta T=\frac{Q}{4 \pi k} \ln \left(\frac{t_{2}-\tau_{0}}{t_{1}-\tau_{0}}\right)
$$

Erros devidos à migração de umidade no produto também existem. Entretanto, por ser um processo transiente, o período de tempo gasto nas determinações é pequeno, ficando esse erro atenuado.

$\mathrm{Na}$ análise de transferência de calor, o produto entre a massa específica e o calor específico é denominado de capacidade calorífica volumar e mede a capacidade do material armazenar energia térmica. A razão entre a condutividade térmica e a capacidade calorífica é uma propriedade importante, conhecida como difusividade térmica, sendo definida por

$$
\alpha=\frac{\mathrm{k}}{\rho \mathrm{c}_{\mathrm{p}}}
$$

em que $\alpha$ é a difusividade térmica $\left(\mathrm{m}^{2} \cdot \mathrm{s}^{-1}\right), \mathrm{c}_{\mathrm{p}}$ é o calor específico $\left(\mathrm{J} \mathrm{kg}^{-1} \cdot{ }^{\circ} \mathrm{C}^{-1}\right), \rho$ é a massa específica $\left(\mathrm{kg} \cdot \mathrm{m}^{-3}\right)$.

A difusividade térmica mede a relação entre a capacidade de o material conduzir energia térmica e a sua capacidade em acumular energia térmica. Materiais com difusividade grande respondem rapidamente às variações do ambiente térmico.

$\mathrm{Na}$ maioria dos processos agrícolas, o teor de água, a temperatura, a massa específica e a porosidade variam consideravelmente a cada etapa e de ponto a ponto no interior de uma massa de grãos, tendo como resultado uma difusividade térmica variável dentro de um determinado processamento. Os métodos normalmente utilizados para determinação da difusividade térmica são: estacionários, transitórios ou por meio da equação 4. Reidy e Rippen (1971) descreveram detalhadamente esses métodos.

Calor específico de um material pode ser definido como a quantidade de energia térmica $(\mathrm{J})$ necessária para elevar a temperatura de um grau Celsius por unidade de massa.

$$
c_{\mathrm{p}}=\frac{\mathrm{Q}}{(\rho \mathrm{V}) \Delta T}
$$

em que V é o volume da amostra $\left(\mathrm{m}^{3}\right)$.

Mohsenin (1980) descreve alguns métodos utilizados para se medir o calor específico de produtos agrícolas. Entre esses, cita-se o método das misturas, por ser o método mais comumente utilizado em pesquisas para determinação de calor específico de grãos e sementes.

Quando são conhecidos os valores de massa específica, condutividade térmica e difusividade térmica, valores de calor específico de um material podem também ser obtidos por meio da equação 4 .

Dos muitos dados relacionados com propriedades térmicas de produtos agrícolas, poucos podem ser considerados confiáveis. A maioria dos valores encontrados na literatura não inclui a faixa de validade. Uma informação precisa deve incluir descrição detalhada do produto, da temperatura e dos erros envolvidos nas medidas. Essa descrição deveria incluir o cultivar, o tamanho individual dos grãos, maturidade e pré-tratamentos nas amostras. No detalhamento experimental, deveriam ser incluídos o tamanho de amostra, condições de superfície, porosidade, temperatura, umidade relativa, pressão atmosférica e procedimento de amostragem. Na descrição do equipamento usado para as determinações, deveriam conter detalhes suficientes, de forma que a experiência pudesse ser repetida. Comparações de fórmulas matemáticas publicadas por diferentes autores mostram que os valores estimados para o calor específico do trigo podem variar em 15\% (MOHSENIN, 1980).

O modelamento da transferência de calor em produtos agrícolas requer o conhecimento de suas

Ciênc. agrotec., Lavras, v. 28, n. 3, p. 488-498, maio/jun., 2004 
propriedades térmicas. São poucas, entretanto, as informações disponíveis sobre as propriedades físicas dos produtos agrícolas produzidos no Brasil. Essa deficiência explica a utilização muito restrita de técnicas de modelagem físico-matemática, tanto para o processamento de produto agrícolas e alimentícios quanto para a elaboração de projetos (SOARES, 1988).

Em vista do exposto, com este trabalho teve-se por objetivo a determinação das propriedades relacionadas com a transferência de calor em massa de grãos de milho em função do teor de água das amostras.

\section{MATERIAL E MÉTODOS}

O presente trabalho foi realizado na área de préprocessamento de produtos agrícolas (Departamento de Engenharia Agrícola) e no Laboratório de Análise de Sementes (Departamento de Fitotecnia), do Centro de Ciências Agrárias da Universidade Federal de Viçosa, Viçosa - MG. Foram utilizados grãos de milho (Zea mays L.) da variedade Vencedor, provenientes da safra de janeiro de 2000 e procedentes do município de Viçosa-MG.

Antes de iniciar o estudo das propriedades térmicas, o teor de água e a massa específica das amostras de grãos de milho foram determinados. Foram investigadas amostras com cinco teores de água $(8,6 ; 11,1 ; 13,1 ; 15,8 \mathrm{e}$ $17,1 \%$ b.u.), obtidas por meio de secagens em ar ambiente.

O teor de água dos grãos, em todas as etapas envolvidas no trabalho, foi determinado pelo métodopadrão da estufa, $105 \pm 3^{\circ} \mathrm{C}$, durante $24 \mathrm{~h}$, com três repetições, de acordo com as Regras para Análise de Sementes (BRASIL, 1992).

A massa específica aparente das amostras foi determinada utilizando-se balança de peso hectolítrico, com capacidade para um quarto de litro, da marca Dallemole, em três determinações. Na determinação da condutividade térmica e da difusividade do produto, foi utilizado o método do cilindro infinito com uma fonte de calor, linear, central.

O equipamento adotado foi projetado e construído no Laboratório de Pré-Processamento de Produtos
Agrícolas do Departamento de Engenharia Agrícola, UFV.

O equipamento (Figura 1) consiste de um tubo de alumínio $(0,1 \mathrm{~m}$ de diâmetro e $0,5 \mathrm{~m}$ de altura) isolado nas extremidades superior e inferior (isopor e cortiça). O cilindro foi construído de maneira a se obter uma transferência de calor, unidimensional, radial, ou seja, mantendo relação entre o comprimento e o raio maior ou igual a dez (INCROPERA e WITT, 1996). Para funcionar como fonte linear de calor, instalou-se no centro do cilindro (longitudinalmente) um fio resistor de níquel-cromo envernizado (resistência aproximada de 4,16 $\Omega \cdot \mathrm{m}^{-1}$ ), com diâmetro de $0,0006438 \mathrm{~m}$. A fonte de calor foi mantida tracionada, ao longo do eixo central do cilindro, por meio de presilhas conectadas às extremidades do cilindro. Três termopares "tipo $\mathrm{T}$ " (cobre-constantan) foram instalados na altura média do cilindro, na direção radial. $\mathrm{O}$ primeiro termopar foi colocado na superfície do fio resistor; o segundo, distanciado de $1 \mathrm{~cm}$ do primeiro, e o terceiro, na superfície interna da parede do cilindro receptor da amostra. Os termopares foram conectados a uma placa de aquisição de dados e as temperaturas detectadas nas três posições, durante a realização de cada experimento, foram registradas em intervalos de 1 segundo.

Durante cada determinação, o fio resistor foi submetido à diferença de potencial de $2,08 \mathrm{~V}$ (fonte alimentadora de tensão e voltagem), que proporcionou corrente elétrica de $1 \mathrm{~A}$.

Antes de cada experimento realizado para a determinação das propriedades térmicas das amostras de milho, o produto, acondicionado em sacos plásticos, foi submetido aos seguintes procedimentos sucessivos: (a) permanência em câmara "B.O.D." $\left(20^{\circ} \mathrm{C}\right)$ por um período de 6 horas até atingir o equilíbrio térmico com o ambiente; (b) transferência para o interior do cilindro (Figura 1), por meio de um equipamento homogeneizador; (c) o sistema (cilindrogrãos) foi transferido para dentro da câmara onde permaneceu até atingir, novamente, o equilíbrio térmico e, (d) finalmente, era fornecida energia ao fio resistor e, simultaneamente, iniciou-se a aquisição dos dados de temperatura. 


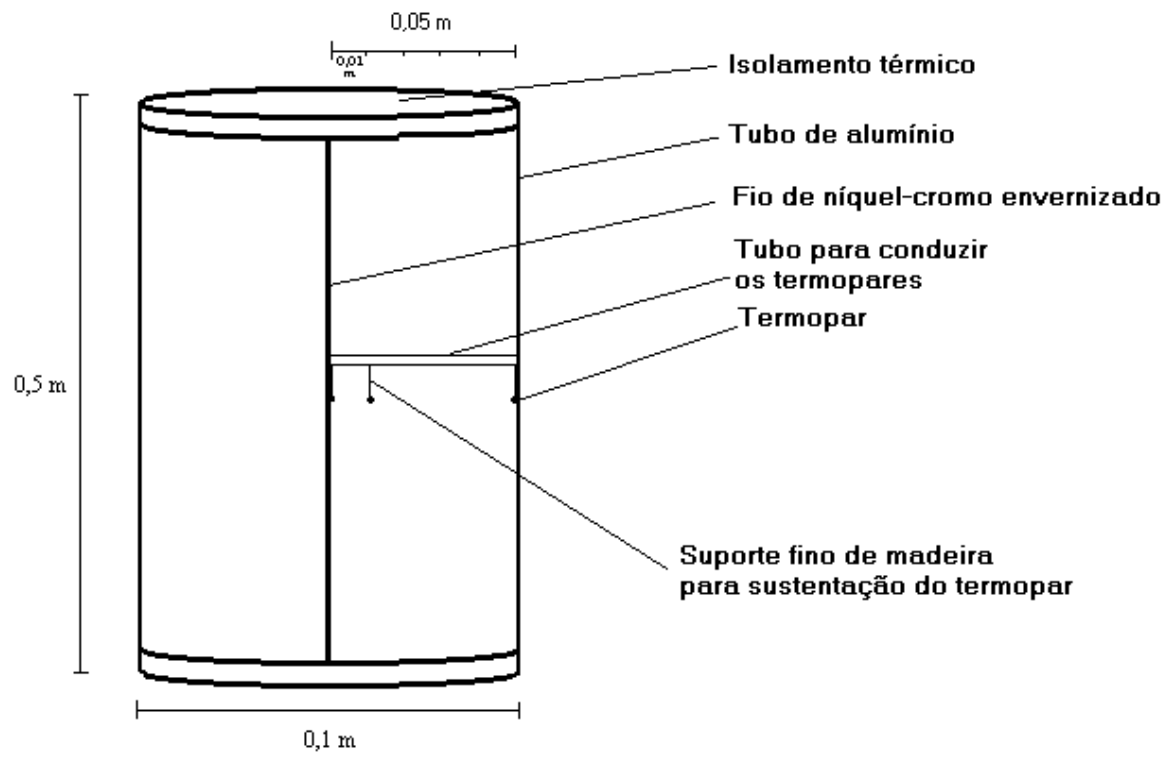

FIGURA 1 - Desenho esquemático do dispositivo experimental para determinação das propriedades térmicas.

Para a determinação da condutividade térmica das amostras de milho, foram alocados na equação (3) os dados das temperaturas e dos tempos correspondentes, provenientes do primeiro termopar, o mais próximo à fonte e cuja distância radial $(0,0003219 \mathrm{~m})$ foi considerada igual ao raio do fio resistor.

Para determinar a difusividade térmica das amostras de milho, foi utilizada a mesma montagem experimental usada para a determinação da condutividade térmica. A massa de grãos foi acomodada no interior do cilindro com uma fonte de geração de calor central. A difusividade térmica do produto foi obtida por meio da equação 6 , considerando intervalos de tempo maiores (CARSLAW e JAEGER, 1959):

$$
\alpha=\frac{e^{\left(\frac{4 \Delta T \pi k}{Q}+\gamma\right)}}{4 t} r^{2}
$$

em que $\gamma=0,5772$ é a constante de Euler, e r é a distância radial.

Para utilizar-se a equação 6 , há necessidade de conhecer a quantidade de calor gerada pela fonte, a condutividade térmica, o gradiente de temperatura no ponto de leitura e o intervalo de tempo em que foram feitas as leituras. Tomou-se o cuidado durante os experimentos para que a variação de temperatura, na massa de grãos, não provocasse migração de umidade significativa.

Após a determinação da difusividade térmica, condutividade térmica e massa específica, o calor específico foi determinado por meio da equação 4 .

As incertezas envolvidas na utilização da equação (3), para se obter a condutividade térmica das amostras, podem ser estimadas por meio da equação (HOLMAN, 2000):

$|d k|=\sqrt{\left(\frac{L}{\Delta T} d q\right)^{2}+\left(\frac{q}{\Delta T} d L\right)^{2}+\left(\frac{q L}{-\Delta T^{2}} d q\right)^{2}}$

\section{RESULTADOS E DISCUSSÃO}

Os valores obtidos experimentalmente para a massa específica aparente de grãos de milho a diferentes teores de água são apresentados na Figura 2 , bem como a equação de regressão ajustada. Observa-se que os valores da massa específica dos grãos de milho aumentam à medida que o teor de água diminui, o que pode ser explicado pela maior contração do volume da amostra de grãos, em relação à redução de massa, durante a secagem do produto.

Os valores estimados de calor específico para amostras de grãos de milho a diferentes teores de água são apresentados na Figura 2. Observa-se que os valores de calor específico aumentam à medida que se eleva o 
teor de água das amostras. A equação ajustada, regressão, para expressar a variação do calor específico em função do teor de água é apresentada também na Figura 2.

Os valores determinados neste trabalho para o calor específico das amostras de milho são semelhantes aos valores recomendados em ASAE (2000).

Os valores da condutividade térmica e da difusividade térmica do milho foram obtidos realizando-se apenas um experimento. Os dados de temperatura foram coletados na massa de grãos no interior do cilindro em uma distância radial específica para a determinação de cada propriedade investigada.

Na Tabela 1, observam-se os valores obtidos para a condutividade térmica dos grãos de milho, juntamente com os tempos utilizados para o cálculo dos respectivos valores da grandeza. Observa-se que o desvio experimental médio foi igual a $0,005 \mathrm{~W} \cdot \mathrm{m}^{-1} .{ }^{\circ} \mathrm{C}^{-1}$ ou seja, aproximadamente $3 \%$. Pode-se observar também que a inclinação da reta sofreu influência direta do teor de água das amostras; para amostras com teores de água maiores, as inclinações da reta obtidas foram menores.

Na Figura 3 podem ser observados os valores experimentais e estimados da condutividade térmica da massa de grãos de milho, em função do teor de água dos grãos. Observa-se que os valores da condutividade térmica da massa de grãos de milho aumentam com o teor de água dos grãos. A equação que expressa a condutividade térmica dos grãos de milho em função de seu teor de água pode ser escrita como:

$$
\mathrm{k}=[0,00434 \mathrm{U}+0,10473] \pm 0,005014
$$

sendo o valor $(0,005014)$ a incerteza média relacionada com a determinação da condutividade térmica para massa de grãos de milho.

Na Figura 4 pode-se observar a variação temporal dos valores da difusividade térmica obtidos pela equação 6, para amostras de grãos de milho em diferentes teores de água. Observa-se que a difusividade térmica é função do teor de água da amostra de grãos de milho: quanto mais seca a massa de grãos, maior é a sua difusividade. Verifica-se, também, a validade da recomendação de Carslaw e Jaeger (1959) sobre utilização da Equação 6 somente para grandes intervalos de tempo experimentais. Pelos resultados experimen- tais, verificou-se que intervalos de tempo superiores a 1000 segundos eram adequados para a obtenção de valores para a difusividade térmica das amostras de milho. Após esse período de tempo, as curvas, inicialmente exponenciais, tenderam à linearidade e proporcionaram valores de difusividade coerentes com a realidade, considerando-se que o produto utilizado é de cultivar brasileira. Neste trabalho, foi utilizado intervalo de tempo de 1000 a 1500 segundos para a determinação da difusividade térmica das amostras. Os valores de difusividade térmica determinados para amostras de grãos de milho a teores de água na faixa de 8,6 a $17,1 \%$ b.u. variaram de $1,22 \times 10^{-7}$ a $1,15 \times 10^{-7} \mathrm{~m}^{2} \cdot \mathrm{s}^{-1}$, respectivamente. Os valores de difusividade, determinados neste trabalho, encontramse próximos daqueles apresentados em ASAE (2000), que variam entre $1,02 \times 10^{-7}$ e $8,67 \times 10^{-8} \mathrm{~m}^{2} \mathrm{~s}^{-}$ 1 , para os teores de água de 0,9 a $20,1 \%$ b.u., respectivamente. A variação da difusividade térmica de amostras de grãos de milho determinada por regressão, em função do teor de água do produto, pode ser expressa por:

$$
\begin{aligned}
& \alpha=-7,999 \times 10^{-10} \mathrm{U}+1,281 \times 10^{-7} \mathrm{~m}^{2} \mathrm{~s}^{-1} \\
& \left(\mathrm{R}^{2}=0,916\right)
\end{aligned}
$$

Nas determinações da difusividade térmica da massa de grãos de milho, foram usadas as temperaturas de pontos localizados a $1 \mathrm{~cm}$ da fonte linear.

Resultados de propriedades térmicas semelhantes com os apresentados neste trabalho foram encontrados em diversas bibliografias para diversos produtos agrícolas, como milho (SOARES, 1988), milheto (ANDRADE et al., 2000), trigo (MUIR e VIRAVANICHAI, 1972), amendoim em casca (WRIGHT e POTERFIELD, 1970), sorgo (SHARMA e THOMPSON, 1973).

As incertezas envolvidas nas determinações das condutividades de amostras de milho a diferentes teores de água, durante os dez primeiros segundos dos experimentos, são apresentados na Tabela 2. Observa-se que os valores de condutividade calculados, usando-se dados experimentais relativos aos quatro segundos iniciais, envolvem as maiores incertezas. Esse período de tempo inicial foi excluído para o cálculo da condutividade térmica e o tempo de 4 segundos foi considerado como o tempo de correção. 


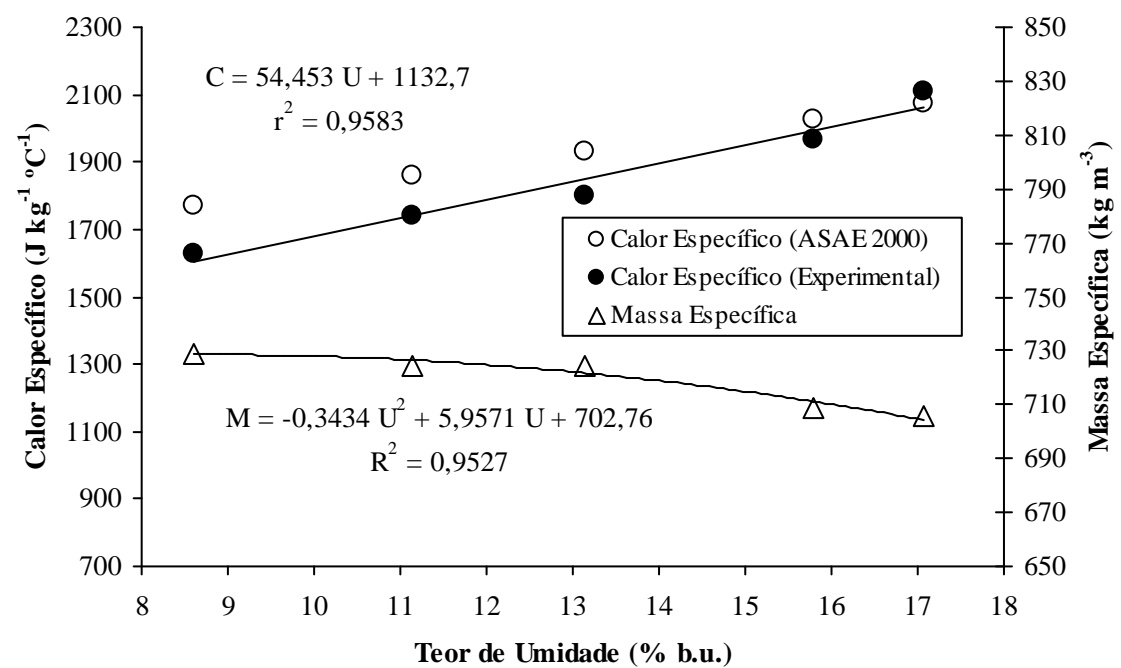

FIGURA 2 - Valores experimentais e estimados do calor específico e da massa específica de grãos de milho, em função do teor de água.

TABELA 1 - Condutividade térmica da massa de grãos de milho com diferentes teores de água e seus respectivos desvios-padrão.

\begin{tabular}{|c|c|c|c|c|c|}
\hline $\begin{array}{l}\text { Teor de água } \\
\text { (\% b.u.) }\end{array}$ & Inclinação da reta & $\mathbf{K}_{\left.\mathbf{m}^{-1}{ }^{\mathbf{o}} \mathbf{C}^{-1}\right)}^{(W}$ & $\begin{array}{l}\text { Tempo } \\
\text { (s) }\end{array}$ & $\begin{array}{c}\text { Media } \\
\left(\mathbf{W} \mathbf{m}^{-1}{ }^{\circ} \mathbf{C}^{-1}\right)\end{array}$ & $\begin{array}{c}\text { Desvio Padrão } \\
\left(\mathbf{W} \mathbf{m}^{-1}{ }^{\mathbf{o}} \mathbf{C}^{-1}\right)\end{array}$ \\
\hline \multirow{3}{*}{8,6} & 2,486 & 0,1332 & 300 & \multirow{3}{*}{0,139} & \multirow{3}{*}{0,0054} \\
\hline & 2,307 & 0,1435 & 200 & & \\
\hline & 2,345 & 0,1412 & 200 & & \\
\hline \multirow{2}{*}{11,1} & 2,113 & 0,1567 & 200 & \multirow{2}{*}{0,157} & \multirow{2}{*}{0,0011} \\
\hline & 2,092 & 0,1583 & 200 & & \\
\hline \multirow{3}{*}{13,1} & 1,977 & 0,1674 & 300 & \multirow{3}{*}{0,162} & \multirow{3}{*}{0,0066} \\
\hline & 2,007 & 0,1649 & 300 & & \\
\hline & 2,136 & 0,1550 & 300 & & \\
\hline \multirow{3}{*}{15,8} & 2,064 & 0,1604 & 250 & \multirow{3}{*}{0,169} & \multirow{3}{*}{0,0079} \\
\hline & 1,893 & 0,1750 & 250 & & \\
\hline & 1,912 & 0,1732 & 250 & & \\
\hline \multirow{3}{*}{17,1} & 1,790 & 0,1850 & 270 & \multirow{3}{*}{0,180} & \multirow{3}{*}{0,0040} \\
\hline & 1,860 & 0,1780 & 300 & & \\
\hline & 1,860 & 0,1780 & 290 & & \\
\hline
\end{tabular}

Ciênc. agrotec., Lavras, v. 28, n. 3, p. 488-498, maio/jun., 2004 


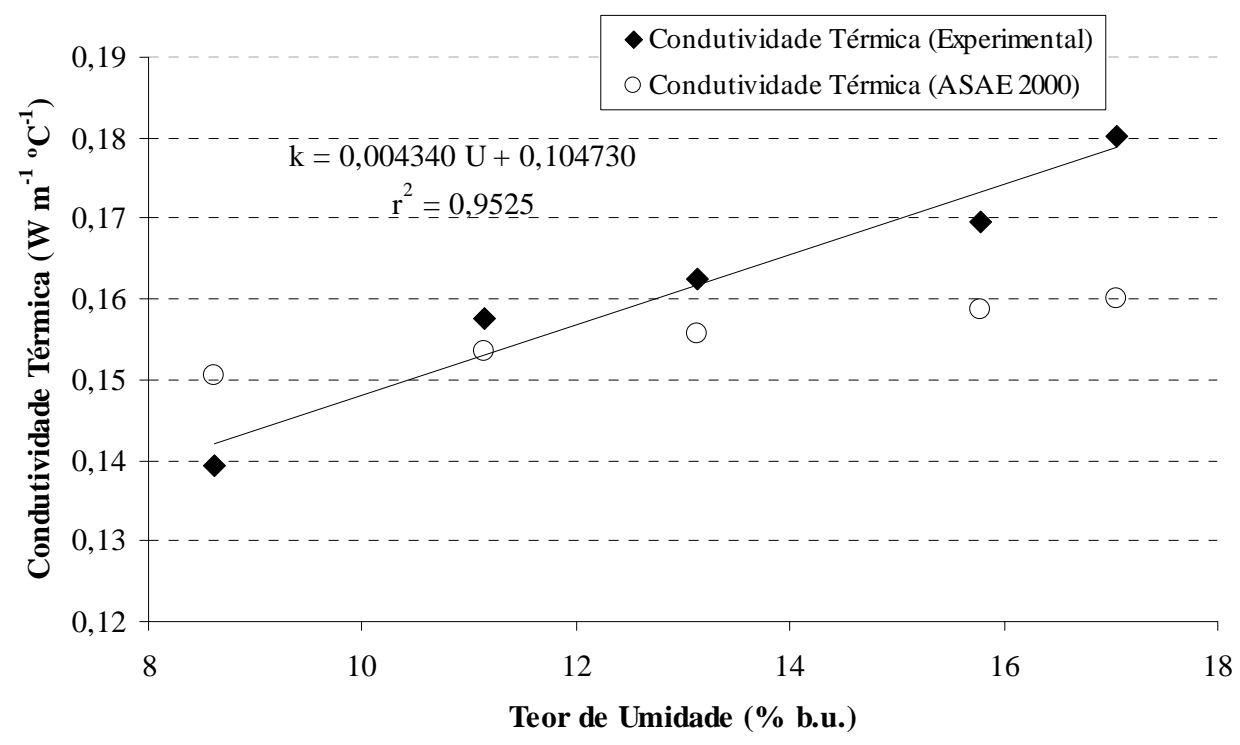

FIGURA 3 - Valores experimentais e estimados da condutividade térmica da massa de grãos de milho, em função do teor de água.

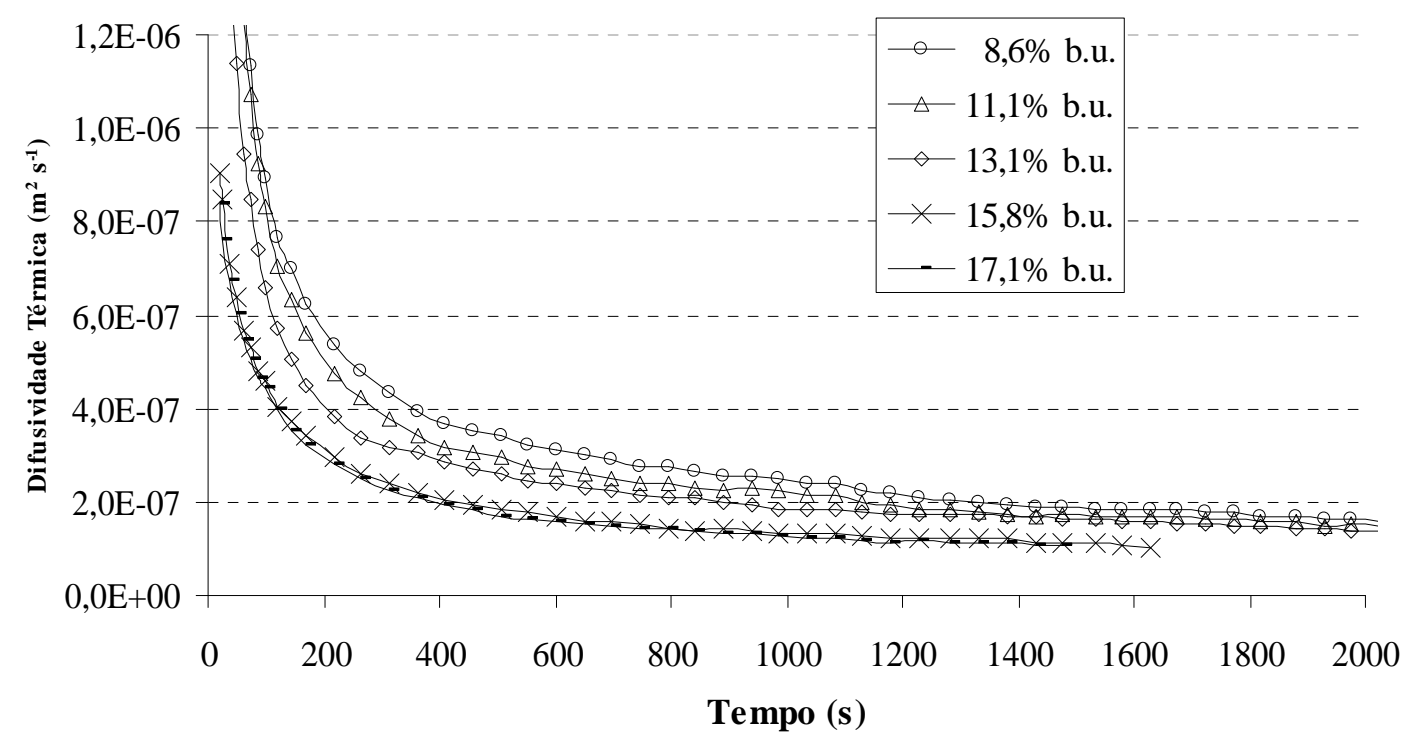

FIGURA 4 - Curvas selecionadas para determinação da difusividade térmica em função da condutividade térmica e do tempo, para milho nos diversos teores de água. 
TABELA 2 - Erros $\left(\mathrm{W} . \mathrm{m}^{-1} \cdot{ }^{\circ} \mathrm{C}^{-1}\right)$ envolvidos no cálculo da condutividade térmica durante os 10 primeiros segundos de experimento.

\begin{tabular}{cccccccc}
\hline \multirow{2}{*}{$\begin{array}{c}\text { Tempo } \\
(\mathbf{s})\end{array}$} & $\mathbf{8 , 6}$ & $\mathbf{1 1 , 1}$ & $\mathbf{1 3 , 1}$ & $\mathbf{1 5 , 8}$ & $\mathbf{1 7 , 1}$ & Média & Erro (\%) \\
\cline { 2 - 8 } & 0,001001 & 0,000139 & 0,007650 & 0,033813 & 0,009100 & 0,010341 & 6,13 \\
\hline 1 & 0,000751 & 0,000120 & 0,001926 & 0,140399 & 0,002892 & 0,029217 & 17,26 \\
2 & 0,000601 & 0,000109 & 0,000738 & 0,005095 & 0,001350 & 0,001579 & 0,94 \\
3 & 0,000401 & $9 \times 10^{-5}$ & 0,000342 & 0,001373 & 0,000588 & 0,000559 & 0,34 \\
4 & 0,000244 & $6,88 \times 10^{-5}$ & 0,000190 & 0,000644 & 0,000369 & 0,000303 & 0,18 \\
6 & 0,000162 & $5,57 \times 10^{-5}$ & 0,000123 & 0,000365 & 0,000225 & 0,000186 & 0,11 \\
7 & 0,000117 & $4,81 \times 10^{-5}$ & $9,49 \times 10^{-5}$ & 0,000234 & 0,000162 & 0,000131 & 0,08 \\
8 & $8,62 \times 10^{-5}$ & $3,89 \times 10^{-5}$ & $6,65 \times 10^{-5}$ & 0,000165 & 0,000118 & $9,5 \times 10^{-5}$ & 0,06 \\
9 & $7,00 \times 10^{-5}$ & $3,31 \times 10^{-5}$ & $5,40 \times 10^{-5}$ & 0,000129 & $9,56 \times 10^{-5}$ & $7,64 \times 10^{-5}$ & 0,05 \\
10 & $5,47 \times 10^{-5}$ & $2,92 \times 10^{-5}$ & $4,31 \times 10^{-5}$ & $9,81 \times 10^{-5}$ & $7,82 \times 10^{-5}$ & $6,07 \times 10^{-5}$ & 0,04 \\
\hline
\end{tabular}

Deve-se ressaltar que a incerteza experimental nos valores de condutividade térmica, em razão de variações entre as amostras de milho testadas (aproximadamente 3\%), é maior do que aquela envolvida ao se usar a equação 3 .

A utilização do método do cilindro infinito dotado de uma fonte de calor linear apresenta um outro tipo de problema relacionado à variação de temperatura, à qual a amostra ficará submetida durante o teste. Grande variação de temperatura pode causar migração de umidade no produto e, conseqüentemente, secagem do produto. A variação máxima de temperatura durante os experimentos para a obtenção dos dados usados na determinação de condutividade e difusividade foi de aproximadamente $11^{\circ} \mathrm{C}$. Exemplo disso é apresentado na Figura 5, na qual se pode observar também a equação ajustada para obtenção da inclinação da reta. A escolha do teor de água de $13,1 \%$ b.u. para esse exemplo foi pelo fato de esse teor de água estar dentro das margens estabelecidas para o armazenamento seguro de uma massa de grãos de milho.

Nix et al. (1967), citados por Almeida (1979), analisaram os erros envolvidos em instrumentos semelhantes e concluíram que dois fatores constituem importantes fontes de erro: o comprimento finito da fonte de calor e as propriedades térmicas da fonte. Esses dois fatores contribuem para o erro relacionado ao intervalo de tempo durante o qual a própria fonte utiliza energia para o aumento de sua vibração molecular.

A utilização das equações 3 e 6 para determinação das propriedades térmicas do milho são válidas para uma fonte de calor linear ideal (comprimento infinito), imersa em um meio infinito. Porém, as determinações experimentais são realizadas com amostras de tamanho finito e a fonte de calor também possui dimensões finitas. Assim, ocorrem erros envolvidos nos resultados de condutividade e difusividade provenientes do emprego dessas equações. Os principais erros envolvidos na metodologia empregada podem ser listados como: a) erro embutido nas equações 3 e 6 devido ao abandono de termos na equação original; b) erro introduzido devido ao comprimento finito da fonte; c) erro causado pela natureza finita do diâmetro da fonte; d) erro resultante do tamanho da amostra; e) erro oriundo da desconsideração da resistência de contato entre a fonte de calor e o material de teste; f) contato termopar-grão: pode ocorrer a possibilidade de grãos do material amostrado não ficarem em contato direto com o termopar, possibilitando pequena camada de ar entre o grão e o termopar; g) erro resultante da compactação da amostra no cilindro; h) posicionamento dos termopares no interior do cilindro; i) erro resultante de trocas de calor entre o ambiente e a amostra; j) migração de umidade e aquecimento da amostra no período de realização do teste. 


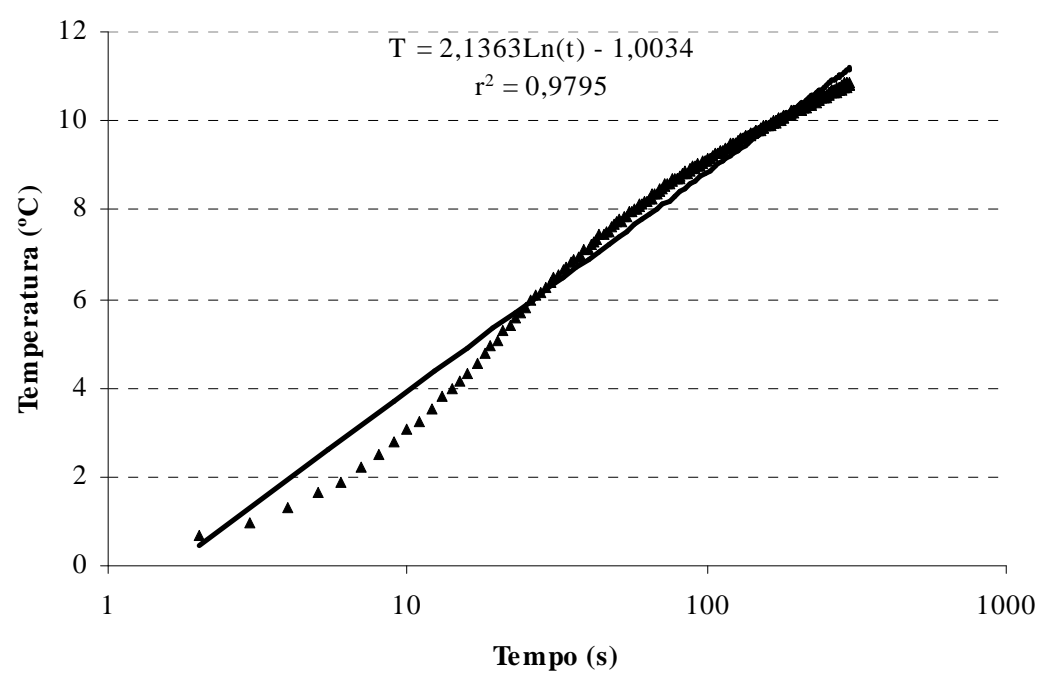

FIGURA 5 - Temperatura versus tempo experimental para grãos de milho com umidade de 13,1\% b.u.

\section{CONCLUSÕES}

Pelos resultados obtidos neste trabalho, para as propriedades térmicas de amostras de milho com teor de água na faixa de 8,6 a $17,1 \%$ b.u., pode-se concluir que:

a) A variação dos valores da condutividade térmica de amostras de milho em função do teor de água (U) do produto pode ser expressa por: $\mathrm{k}=0,00434 \mathrm{U}+$ $0,10473( \pm 0,00501) \mathrm{W} \mathrm{m}^{-1}{ }^{\mathrm{o}} \mathrm{C}^{-1}$. $\mathrm{O}$ erro aproximado na utilização dessa equação é de $3 \%$;

b) O calor específico de amostras de milho em função do teor de água pode ser representado por: $\mathrm{C}=$ $54,453 \mathrm{U}+1332,7 \mathrm{~J} \mathrm{~kg}^{-1}{ }^{\circ} \mathrm{C}^{-1}$;

c) A variação da difusividade térmica de amostras de grãos de milho em função do teor de água do produto pode ser expressa por: $\alpha=-7,999 \times 10^{-10} \mathrm{U}+$ $1,281 \times 10^{-7} \mathrm{~m}^{2} \mathrm{~s}^{-1}\left(\mathrm{r}^{2}=0,916 \%\right)$

\section{REFERÊNCIAS BIBLIOGRÁFICAS}

ALMEIDA, B. V. Determinação de propriedades físicas de amêndoas de cacau (Theobroma cacao, L.). 1979. 70 f. Dissertação (Mestrado em Engenharia Agrícola) - Universidade Federal de Viçosa, Viçosa, 1979.

ANDRADE, E. T.; CORREA, P. C.; AFONSO JÚNIOR, P. C. Propriedades térmicas da massa granular de milheto [Penissetum americanum (L.) Leeke]. In: Avances en ingenieria agrícola. Buenos Aires: Facultad de Agronomia, 2000. p. 545-550.

\section{AMERICAN SOCIETY OF AGRICULTURAL ENGINEERS. Agricultural Engineers Yearbook. Saint Joseph: Michigan, 2000. 796 p.}

BRASIL. Ministério da Agricultura e Reforma Agrária. Regras para análise de sementes. Brasília, DF, 1992. $365 \mathrm{p}$.

CARSLAW, H. S.; JAEGER, N. C. The conduction of heat in solids. 2. ed. London: Oxford University, 1959. $510 \mathrm{p}$.

CHANDRA, S.; MUIR, W. E. Thermal conductivity of spring wheat at low temperature. Transactions of the ASAE, Saint Joseph, v. 14, p. 644-646, 1971.

DICKERSON, R. W. An apparatus for the measurement of thermal diffusivity of foods. Food Technology, Chicago, p. 198-204, May 1965.

DROUZAS, A.E.; SARAVACOS, G. D. Effective thermal conductivity of granular starch materials. Journal of Food Science, Athens, v. 53, n. 6, p. 1795-1799, 1988.

FANG, Q.; LAN, Y.; KOCHER, M. F.; HANNA, M. A. Thermal conductivity of granular starch materials. Transactions of the ASAE, Saint Joseph, n. 97, p. 18, 1997.

HOLMAN, J. P. Experimental methods for engineers. New York: McGraw-Hill International, 2000. 720 p. 
HOOPER, F. C.; LEPPER, F. R. Transient heat flow apparatus for the determination of thermal conductivities. Transactions ASHVE, Saint Joseph, v. 56, p. 309-322, 1950.

INCROPERA, F. P.; WITT, D. P. Fundamentals of heat and mass transfer. New York: John Wiley \& Sons, 1996. 886 p.

JASANSKY, A.; BILANSKI, W. K. Thermal conductivity of whole and ground soybeans. Transactions of the ASAE, Saint Joseph, p. 100-103, 1973.

JAYAS, D. S.; WHITE, N. D. G.; MUIR, W. E. Stored-grain ecosystems. New York: Marcel Dekker, 1995. $756 \mathrm{p}$.

MAROULIS, Z. B.; SHAH, K. K.; SARAVACOS, G. D. Thermal conductivity of gelatinized starches. Journal of Food Science, Chicago, v. 56, n. 3, p. 773 776, 1991.

MOHSENIN, N. N. Thermal properties of foods and agricultural materials. New York: Gordon, 1980. $407 \mathrm{p}$.

MUIR, W. E.; CHANDRA, S. Thermal conductivity of spring wheat at low temperatures. Transactions of the ASAE, Saint Joseph, n. 49, p. 15, 1970.

MUIR, W. E.; VIRAVANICHAI, S. Specific heat of wheat. Journal of Agricultural Engineering Research, Silsoe, v. 17, p. 338-342, 1972.

PASSOS, E. F. Condutividade térmica da pasta de mandioca. Revista Ceres, Viçosa, v. 29, n. 162, p. 222 231, 1982.

REIDY, G. A.; RIPPEN, A. L. Methods for determining thermal conductivity in foods. Transactions of the ASAE, Saint Joseph, v. 14, n. 2, p. 248-254, 1971 .
ROSSI, S. J.; FIOREZE, R.; OLIVEIRA, A. M. C.; MALZAC, H. F. Propriedades térmicas de castanha de cajú e raspa de mandioca. Revista Brasileira de Armazenamento, Viçosa, v. 7, n. 1, p. 51-56, 1982.

ROSSI, S. J.; ROA, G. Secagem e armazenamento de produtos agropecuários com o uso de energia solar e ar natural. São Paulo: Academia de Ciência de Estado de São Paulo, 1980. 295 p.

SHARMA, D. K.; THOMPSOM, T. L. Specific heat and thermal conductivity of sorghum. Transactions of the ASAE, Saint Joseph, v. 16, n. 1, p. 114-117, 1973.

SINGH, R. P. Thermal diffusivity in food processing. Food Technology, Chicago, v. 36, n. 2, p. 87-91, 1982.

SOARES, N. F. F. Análise experimental do método de sonda para medição de condutividade térmica de grãos: Aplicação para milho (Zea mays L.). 1988. 46 f. Dissertação (Mestrado em Ciência e Tecnologia de Alimentos) - Universidade Federal de Viçosa, Viçosa, 1988.

STOLF, S. R. Medição da condutividade térmica dos alimentos. Boletim do Instituto de Tecnologia de Alimentos, Campinas, n. 29, p. 67-79, 1972.

SUTER, D. A.; AGRAWAL, K. K.; CLARY, B. L. Thermal properties of peanut pods, hulls and kernel. Transactions of the ASAE, Saint Joseph, v. 18, n. 2, p. 370-375, 1975.

VOUDOURIS, N.; HAYAKAWA, K. Simultaneous determination of the thermal conductivity and diffusivity of foods using a point heat source probe: a theoretical analysis. Journal of Food Science and Technology, Oxford, v. 27, n. 6, p. 522-532, 1994.

WRIGHT, M. E.; POTERFIELD, J. G. Specific heat of spanish peanuts. Transactions of the ASAE, Saint Joseph, v. 13, n. 4, p. 508-510, 1970. 